\title{
Tuberculosis Mastitis: Fever of Unknown Origin in a Kidney Transplant Recipient
}

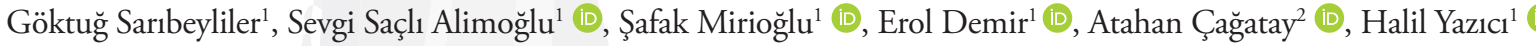 \\ ${ }^{1}$ Division of Nephrology, Department of Internal Medicine, İstanbul University İstanbul School of Medicine, İstanbul, Turkey \\ ${ }^{2}$ Department of Infectious Diseases and Clinical Microbiology, İstanbul University İstanbul School of Medicine, İstanbul, Turkey
}

\begin{abstract}
Tuberculous mastitis is a rare presentation of tuberculosis, which is a major health problem in kidney transplant recipients due to its high incidence and prevalence, and difficulty in diagnosis as well as high risk of morbidity and mortality. In daily practice, physicians may frequently be led to a misdiagnosis such as breast carcinoma or abscess. We believe it is crucial for clinicians to recognize this important presentation of the disease. Therefore, we present a case of tuberculous mastitis in a kidney transplant recipient who was admitted with fever of unknown origin and successfully treated using standard anti-tuberculosis therapy without any complications.
\end{abstract}

Keywords: Tuberculosis mastitis, fever of unknown origin, kidney transplantation, anti-tuberculosis treatment

Cite this article as: Sarıbeyliler G, Saçlı Alimoğlu S, Mirioğlu Ş, Demir E, Çağatay A, Yazıcı H. Tuberculosis Mastitis: Fever of Unknown Origin in a Kidney Transplant Recipient. Eur J Breast Health 2019; 15(4): 272-274.

\section{Introduction}

Tuberculosis (TB) is a major health issue in kidney transplant recipients due to its high incidence and prevalence and difficulty in diagnosis as well as high risk of morbidity and mortality, especially in developing countries. The incidence of tuberculosis is estimated to be $20-74$ times higher in kidney transplant recipients than the general population. Beyond the high incidence, atypical presentations and organ involvements are also frequent in these patients $(1,2)$.

Tuberculous mastitis is one of those rare presentations of TB accounting for less than $1 \%$ of all breast diseases in developed countries, however, its incidence is higher in developing and undeveloped nations where TB is endemic (3-5). It usually occurs as a lump on the central or upper outer quadrant of the breast. Owing to this location and scarce nature of the disease, clinicians may frequently be led to a misdiagnosis such as a breast carcinoma or abscess (6). Here, we present a case with the fever of unknown origin in a kidney transplant recipient due to tuberculous mastitis.

\section{Case Presentation}

A 59-year-old female kidney transplant recipient was admitted with a high fever, loss of appetite and weight loss which had been present for 3 months. The renal transplantation was performed from a living related donor 8 years ago and renal functions remained well on a triple immunosuppressive regimen including tacrolimus, azathioprine and prednisolone. On admission, her body temperature was 38.5 ${ }^{\circ} \mathrm{C}$. Remaining of the examination did not point to a source of infection: No lymphadenopathy was noted, lungs were clear to auscultation, heart sounds were regular without, and her abdomen was not tender.

A laboratory workup revealed a C-reactive protein level of $86 \mathrm{mg} / \mathrm{L}$ and an erythrocyte sedimentation rate of $56 \mathrm{~mm} / \mathrm{h}$. Blood and urine cultures were drawn and broad-spectrum antibiotics were initiated. Computed tomography of the thorax and abdomen revealed no abnormalities. However, during the examination of the left breast, a tender mass with a 1-cm diameter was noticed. Magnetic resonance imaging (MRI) of the breast demonstrated that this lesion was consistent with an abscess (Figure 1). Acid-fast bacilli were present in the sample obtained from the lesion. The patient was started on an empirical anti-tuberculosis treatment regimen with 


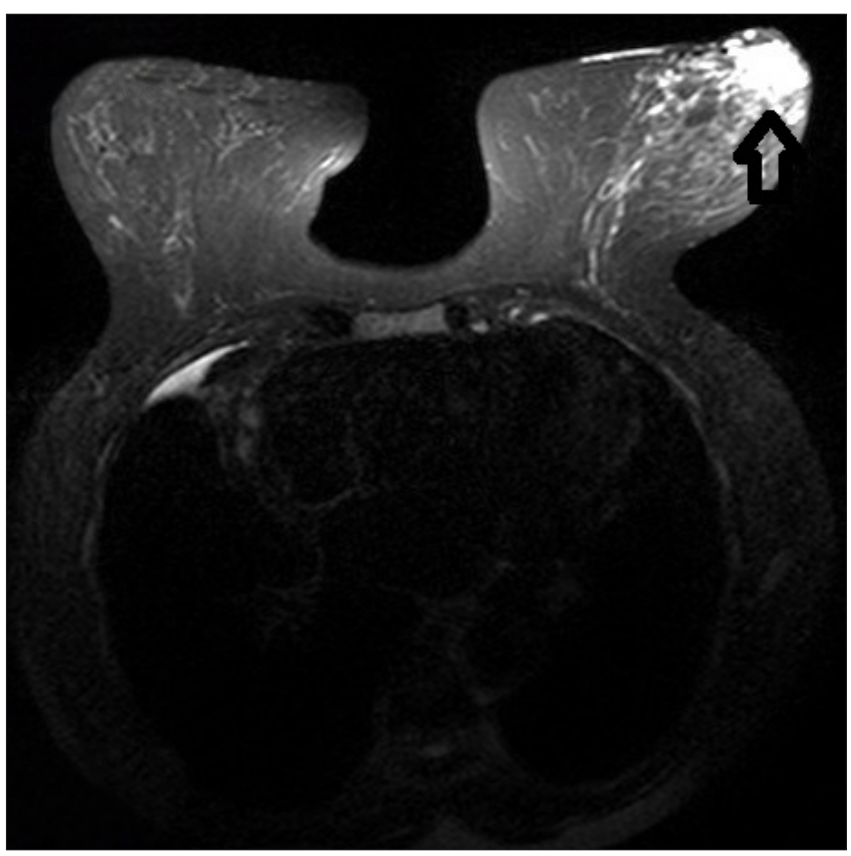

Figure 1. T2-weighted axial MRI image demonstrates a high signalintensity area in the lower outer left breast at anterior depth

isoniazid, rifampicin, pyrazinamide, and ethambutol with the diagnosis of tuberculous mastitis (7-10). Tissue cultures were positive for Mycobacterium tuberculosis.

The treatment was well tolerated, and her fever dissolved after 10 days of treatment. At the end of the 12-month treatment period, the lesion completely disappeared.

Written informed consent was obtained from the patient for publication of this case report and any accompanying images. A copy of the written consent may be requested for review from the corresponding author.

\section{Discussion and Conclusion}

Tuberculosis is one of the most important opportunistic infections in kidney transplant recipients (2). It is more common in patients with kidney transplants when compared to other solid organ transplant recipients who have milder immunosuppressive treatment regimens and longer average lifespan (2).

It is even harder to diagnose tuberculosis in solid organ transplant recipients because of atypical presentations in this group of patients, and increase in negative results of tuberculin skin tests, interferon-gamma release assays, and examinations with Ziehl-Neelsen stain (2). In this particular instance, it should be kept in mind that tuberculous mastitis can mimic breast cancer and other causes of non-tuberculosis granulomatous mastitis (5). Tissue culture and Ziehl-Neelsen staining still remain as gold standards of diagnosis in tuberculous mastitis (6). However, tuberculosis bacilli are isolated in $25 \%$ of the cases with tuberculous mastitis, and acid-fast bacilli are seen in only $12 \%$ of the cases $(7,8)$. Thus, in the absence of microbiologic verification, the presence of a caseous granuloma may be helpful for diagnosis $(7,8)$.

Tuberculous mastitis should be treated using guidelines for pulmonary tuberculosis given the absence of specific guidelines for breast tubercu- losis (10-12). European kidney transplantation guidelines recommend an initial treatment for 2 months using a regimen containing isoniazid, rifampicin, and pyrazinamide (with the addition of ethambutol when dealing with strains showing resistance to isoniazid), which will be followed with isoniazid and rifampicin for an additional 4 months (1012). Treatment duration is recommended to be extended to 12 , even 18 months in immunosuppressed patients based on the studies which showed no recurrence in patients treated for 12 months (10-12). Also, a 9-month therapy was reported with greater mortality (12). Considering these findings and immunocompromised status of our patient, anti-TB treatment was given for 12 months to prevent further relapses.

Maintenance of therapeutic drug levels is an important aspect of tuberculosis treatment. Rifampicin reduces blood levels of tacrolimus, cyclosporine, sirolimus, and everolimus $(13,14)$. Even with proper monitoring, combining rifampicin and tacrolimus increases the frequency of graft rejection and graft loss, and overall TB related mortality $(13,14)$. We increased tacrolimus doses 3 times throughout the treatment period monitoring drug trough level twice a week, and no complications were observed in terms of maintaining an adequate immunosuppressive state thereby preserving graft function.

In conclusion, we have presented a case of tuberculous mastitis in a kidney transplant recipient who was admitted with fever of unknown origin and successfully treated using standard anti-TB therapy without any complications.

Informed Consent: Written informed consent was obtained from patient who participated in this study.

Peer-review: Externally peer-reviewed.

Author Contributions: Concept - A.Ç., H.Y.; Design - A.Ç., H.Y.; Supervision - A.Ç., H.Y.; Resources - Ş.M., E.D.; Materials - Ş.M., E.D.; Data Collection and/or Processing - G.S., S.S.A.; Analysis and/or Interpretation - Ş.M., E.D.; Literature Search - Ş.M., E.D.; Writing Manuscript - G.S., S.S.A., Ş.M., E.D.; Critical Review - A.Ç., H.

Conflict of Interest: The authors have no conflicts of interest to declare.

Financial Disclosure: The authors declared that this study has received no financial support.

\section{References}

1. Tiemersma EW, van der Werf MJ, Borgdorff MW, Williams BG, Nagelkerke NJ. Natural History of Tuberculosis: Duration and Fatality of Untreated Pulmonary Tuberculosis in HIV Negative Patients: A Systematic Review. PLoS One 2011; 6: e17601. (PMID: 21483732) [CrossRef]

2. Mu-oz P, Rodríguez C, Bouza E. Mycobacterium tuberculosis Infection in Recipients of Solid Organ Transplants. Clin Infect Dis 2005; 40: 581 587. (PMID: 15712081) [CrossRef]

3. Marinopoulos S, Lourantou D, Gatzionis T, Dimitrakakis C, Papaspyrou I, Antsaklisa A. Breast tuberculosis: Diagnosis, management and treatment. Int J Surg Case Rep 2012; 3: 548-550. (PMID: 22918083) [CrossRef]

4. Luh SP, Chang KJ, Cheng JH, Hsu JD, Huang CS. Surgical treatment for primary mammary tuberculosis - report of three octogenarian cases and review of literature. Breast J 2008; 14: 311-312. (PMID: 18373505) [CrossRef]

5. Asoglu O, Ozmen V, Karanlik H, Tunaci M, Cabioglu N, Igci A, Selcuk UE, Kecer M. Feasibility of surgical management in patients with granulomatous mastitis. Breast J 2005; 11: 108-114. (PMID: 15730456) [CrossRef]

6. Calıs H, Kilitci A. Granulomatous Mastitis Concurrence with Breast Cancer. Eur J Breast Health 2018; 14: 58-60. (PMID: 29322122) [CrossRef] 
7. Eroglu A, Kurkcuoglu C, Karaoglanoglu N, Kaynar H. Breast mass caused by rib tuberculosis abscess. Eur J Cardiothorac Surg 2002; 22: 324-326. (PMID: 12142213) [CrossRef]

8. Ozsen M, Tolunay S, Gokgoz MS. Case Report: Ductal Carcinoma in Situ Within A Granulomatous Mastitis. Eur J Breast Health 2018; 14: 186-188. (PMID: 30123886) [CrossRef]

9. Gupta D, Rajwanshi A, Gupta SK, Nijhawan R, Saran RK, Singh R. Fine needle aspiration cytology in the diagnosis of tuberculous mastitis. Acta Cytol 1999; 43: 191-194. (PMID: 10097708) [CrossRef]

10. Recep A, Tosun N, Erkoc Y, Buzgan T, Bozkurt H. Republic of Turkey Ministry of Health Tuberculosis Diagnosis and Treatment Guide. Ministry of Health 2011; pp. 99-111.

11. EBPG Expert Group in Renal Transplantation. European best practice guidelines for renal transplantation. Section IV: Long-term management of the transplant recipient. IV.7.2. Late infections. Tuberculosis. Nephrol Dial Transplant 2002; 17: 39-43. (PMID: 12091644)
12. Torre-Cisneros J, Fortún J, Aguado JM, de la Cámara R, Cisneros JM, Gavaldá J, Gurguí M, Lumbreras C, Martín C, Martín-Dávila P, Montejo M, Moreno A, Mu-oz P, Pahissa A, Pérez JL, Rovira M, Bernardos A, GilVernet S, Quijano Y, Rábago G, Román A, Varó E. Tuberculosis in SolidOrgan Transplant Recipients: Consensus Statement of the Group for the Study of Infection in Transplant Recipients (GESITRA) of the Spanish Society of Infectious Diseases and Clinical Microbiology. Clin Infect Dis 2009; 48: 1276-1284. (PMID: 16159543) [CrossRef]

13. Aguado JM, Herrero JA, Gavaldá J, Torre-Cisneros J, Blanes M, Rufí G, Moreno A, Gurguí M, Hayek M, Lumbreras C, Cantarell C. Clinical presentation and outcome of tuberculosis in kidney, liver, and heart transplant recipients in Spain. Transplantation 1997; 63: 1278-1286. (PMID: 9158022) [CrossRef]

14. Offermann G, Keller F, Molzahn M. Low cyclosporine A blood levels and acute graft rejection in a renal transplant recipient during rifampin treatment. Am J Nephrol 1985; 5: 385-387. (PMID: 3904451) [CrossRef] 